\title{
Serum peptide expression and treatment responses in patients with advanced non-small-cell lung cancer
}

\author{
JUAN AN $^{1,2^{*}}$, CHUAN-HAO TANG ${ }^{1 *}$, NA WANG $^{3}$, YI LIU $^{4}$, JIN LV $^{2}$, BIN XU $^{3}$, XIAO-YAN LI ${ }^{1}$, \\ WAN-FENG GUO ${ }^{1}$, HONG-JUN GAO ${ }^{1}, \mathrm{KUN} \mathrm{HE}^{3}$ and XIAO-QING LIU ${ }^{1}$ \\ ${ }^{1}$ Department of Lung Cancer, Affiliated Hospital of Academy of Military Medical Sciences, \\ Beijing 100071; ${ }^{2}$ Department of Oncology, The General Hospital of PLA Rocket Force, Beijing 100088; \\ ${ }^{3}$ National Center of Biomedical Analysis, Academy of Military Medical Sciences, Beijing 100850; \\ ${ }^{4}$ Department of Oncology, Affiliated Hospital of Academy of Military Medical Sciences, Beijing 100071, P.R. China
}

Received September 19, 2016; Accepted January 19, 2018

DOI: $10.3892 / \mathrm{ol} .2018 .8460$

\begin{abstract}
Epidermal growth factor receptor (EGFR) mutation is an important predictor for response to personalized treatments of patients with advanced non-small-cell lung cancer (NSCLC). However its usage is limited due to the difficult of obtaining tissue specimens. A novel prediction system using matrix assisted laser desorption ionization-time of flight mass spectrometry (MALDI-TOF MS) has been reported to be a perspective tool in European countries to identify patients who are likely to benefit from EGFR tyrosine kinase inhibitor (TKI) treatment. In the present study, MALDI-TOF MS was used on pretreatment serum samples of patients with advanced non-small-cell lung cancer to discriminate the spectra between disease control and disease progression groups in one cohort of Chinese patients. The candidate features for classification were subsequently validated in a blinded fashion in another set of patients. The correlation between plasma EGFR
\end{abstract}

Correspondence to: Dr Xiao-Qing Liu, Department of Lung Cancer, Affiliated Hospital of Academy of Military Medical Sciences, 8 Dong-Da Street, Beijing 100071, P.R. China

E-mail: liuxq@medmail.com.cn

*Contributed equally

Abbreviations: EGFR, epidermal growth factor receptor; EGFR-TKI, epidermal growth factor receptor-tyrosine kinase inhibitor; NSCLC, non-small-cell lung cancer; MALDI-TOF MS, matrix-assisted laser desorption ionization-time of flight mass spectrometry; MBS, magnetic bead separator; PFS, progression-free survival; m/z, mass-to-charge ratio; $\mathrm{CR}$, complete response; PR, partial response; SD, stable disease; PD, progressive disease; HCCA, $\alpha$-cyano-4-hydroxycinnamic acid; ECOG, Eastern Cooperative Oncology Group; OS, overall survival

Key words: non-small-cell lung cancer, matrix-assisted laser desorption ionization-time of flight mass spectrometry, tyrosine kinase inhibitor, polypeptide, treatment responses mutation status and the intensities of representative spectra for classification was evaluated. A total of 103 patients that were treated with EGFR-TKIs were included. It was determined that 8 polypeptides peaks were significant different between the disease control and disease progression group. A total of 6 polypeptides were established in the classification algorithm. The sensitivity of the algorithm to predict treatment responses was $76.2 \%(16 / 21)$ and the specificity was $81.8 \%(18 / 22)$. The accuracy rate of the algorithm was $79.1 \%$ (34/43). A total of 3 polypeptides were significantly correlated with EGFR mutations $(\mathrm{P}=0.04, \mathrm{P}=0.03$ and $\mathrm{P}=0.04$, respectively). The present study confirmed that MALDI-TOF MS analysis can be used to predict responses to EGFR-TKI treatment of the Asian population where the EGFR mutation status differs from the European population. Furthermore, the expression intensities of the three polypeptides in the classification model were associated with EGFR mutation.

\section{Introduction}

Lung cancer remains a common cause of mortalities worldwide, accounting for 1.6 million mortalities in 2012 and $\sim 20 \%$ of all cancer mortalities (1). Non-small cell lung cancer (NSCLC) is the predominant type of the disease with $~ 80 \%$ of cases (1). In the last decade, the important discovery of mutations in the epidermal growth factor receptor (EGFR) gene had led to the development of targeted therapy and personalized medicine (2). One class of anti-tumor drugs that target EGFR is a group of small molecule inhibitors that inhibit the tyrosine kinase domain of EGFR, EGFR-tyrosine kinase inhibitors (TKIs). Examples of EGFR-TKIs include gefitinib and erlotinib $(3,4)$.

EGFR-TKIs have demonstrated initial success in some patients with activating mutations (5). However, numerous patients do not respond to the drug (6-8). Therefore, the identification of biomarkers that are predicative of response to the drug became a key issue for doctors to select the optimal therapy. To date, mutations in the EGFR gene (exon 19 deletion, exon 18 G719X and exon 21 L858R) have been reported to be predictors of individualized treatment (9-12). However, obtaining sufficient quantities of tissue specimens 
for laboratory evaluation is a challenge in clinical practice. Unlike large quantities of tissue obtained during surgery, tissue biopsies obtained in patients with advanced NSCLC are usually too small for detection of EGFR gene mutations following pathological diagnosis, such as routine and immunohistochemical staining $(13,14)$. Additionally, under safety and compliance considerations, repeated biopsies of these patients are associated with high risks and therefore are unacceptable. Consequently, there is an urgent need to develop specific biomarkers in specimens that are more easily assessable, such as serum or plasma.

Matrix-assisted laser desorption ionization-time of flight mass spectrometry (MALDI-TOF MS) is a soft ionization technique used in mass spectrometry, which allows the analysis of biomolecules (biopolymers such as DNA, proteins, peptides and sugars) and large organic molecules (such as polymers, dendrimers and other macromolecules), which tend to be fragile and fragment when ionized by more conventional ionization methods $(15,16)$. MALDI-TOF MS is a high-throughput procedure and much faster, more accurate and cheaper compared with other techniques based on immunological or biochemical tests $(17,18)$. In recent years, MALDI-TOF MS has been successfully used in distinguishing cancer patients from healthy controls, such as in pancreatic, breast, ovarian and lung cancer $(19,20)$. With regards to predicting tumor treatment responses, perspective applications of MALDI-TOF MS have also been reported. In 2007, Taguchi et al (21) developed and validated a serum/plasma test (VeriStrat) that uses MALDI-TOF MS to classify patients with NSCLC based on prognosis following treatment with EGFR TKIs. Following the preliminary study, the same group further demonstrated that VeriStrat not only have the predictive capability but also have the potential to be used for monitoring gefitinib treatment (22). However, VeriStrat was performed and evaluated primarily on the Caucasian population, which possess a low frequency of EGFR mutations ( 10\%) (23). The frequency of EGFR mutations in the Asian population is $\sim 30 \%$ (24), therefore, it is also desirable to establish biomarkers using MALDI-TOF MS in this population.

The aim of the present study was to investigate whether MALDI-TOF MS analysis can be used for pretreatment selection of patients with advanced NSCLC, who would benefit from EGFR-TKI therapy in one cohort of Chinese patients. The MALDI-TOF MS data were obtained and further analyzed with advanced chemometric tools.

The spectra that were distinctive between the disease control and disease progression groups of patients were selected in a training set of samples. Subsequently, the candidate features of classification were validated in blinded fashion in the test group of another set of patients. The association between the blood EGFR mutation status and intensities of the representative spectra for classification was also evaluated.

\section{Materials and methods}

Patient follow-up and sample collection. Patients that pathologically confirmed as stage IIIb-IV NSCLC were enrolled at the Department of the Pulmonary Oncology at the Hospital of Military Medical Sciences (Beijing, China) between August 2011 and October 2012. The inclusion criteria included $\geq 18$ years old and Eastern Cooperative Oncology Group (ECOG) performance status $(25,26) \leq 3$. EGFR-TKIs therapies, including gefitinib, erlotinib and icotinib were administrated with the recommended dose. CT scan was initially performed after four weeks of EGFR-TKI treatment and was continuously performed every two months. All patients were followed up until July 31, 2013. The best overall efficacies were divided into five groups: Complete response (CR), partial response (PR), stable disease (SD), progressive disease (PD) according to Response Evaluation Criteria for Solid Tumors (version 1.1) (27).

All serum samples were collected prior to the initial treatment of EGFR-TKIs. The sera were separated into aliquots $(150 \mu \mathrm{l})$ and centrifuged at $2,500 \mathrm{x}$ for $10 \mathrm{~min}$ at $4^{\circ} \mathrm{C}$. The samples were then put into liquid nitrogen for rapid freezing and stored at $-80^{\circ} \mathrm{C}$.

The present study was approved by the Ethics Committee of Academy of Military Medical Sciences in accordance with the medical research regulations of China and conformed to the provisions of the Declaration of Helsinki in 1995 (as revised in Tokyo 2004) (28). All participants provided written informed consent, and patient information was used anonymously.

Isolation of serum polypeptides. Briefly, the serum samples were thawed on ice. Resuspended MB-IMAC-Cu ${ }^{2+}$ (National Center of Biomedical Analysis, Beijing, China) was mixed with $5 \mu \mathrm{l}$ beads (National Center of Biomedical Analysis) in $50 \mu \mathrm{l}$ binding buffer (National Center of Biomedical Analysis) and applied onto the magnetic bead separator (MBS; Bruker Corporation, Ettlingen, Germany) for four times. The supernatant was subsequently discarded, and the procedure was repeated three times. Subsequently, $5 \mu 1$ serum was mixed with $20 \mu 1$ binding buffer without disturbance at room temperature for $10 \mathrm{~min}$. The mixture was applied onto the MBS for four times, and the supernatant was discarded. A total of $100 \mu \mathrm{l}$ washing solution was added following the MBS step (four times), and the supernatant was discarded. This step was repeated twice. A total of $20 \mu \mathrm{l}$ elution buffer was added and mixed at room temperature for $20 \mathrm{~min}$. The final mixture was placed on the MBS for four times and stood for $20 \mathrm{sec}$ each time. Finally, the supernatant containing serum polypeptide was collected.

MALDI-TOF MS analysis. The samples were analyzed at the Beijing Proteome Research Center (Beijing, China) using a Bruker Autoflex-II MALDI MS (Bruker Corporation). The serum polypeptides were mixed with $1 \mu \mathrm{l}$ saturated HCCA matrix ( $\alpha$-cyano-4-hydroxycinnamic acid dissolved in $0.1 \%$ trifluoroacetic acid and 50\% acetonitrile) and was spotted at a unique location on the target plate. The plate was dried at room temperature and then inserted into the mass spectrometer after the instrument was calibrated with pure, well-characterized standards. Positive ion mass spectra were obtained in linear mode in an automated manner. The mass spectrum comprised peaks of the polypeptides with different mass-to-charge ratio $(\mathrm{m} / \mathrm{z})$, which was obtained using the software ClinProTools (CPT; Bruker Corporation). To avoid system errors and manual operation errors, the standard (peptide mixture) would be detected prior to the testing of each sample. Meanwhile, 10 cases were randomly selected, and their serum samples were collected for 6 days. 


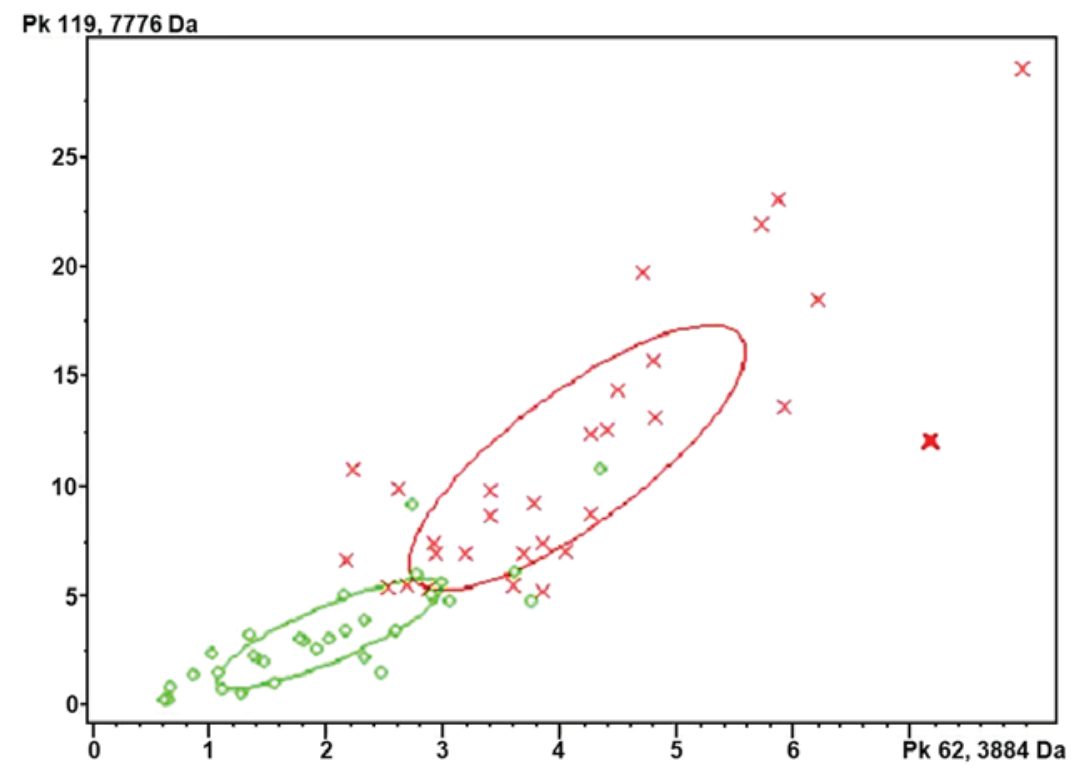

Figure 1. Cluster analysis of serum polypeptides of the control group (red) and progressive disease group (green).

In order to evaluate the inter-stability of MALDI-TOF MS analysis, samples from the same patient but collected on different days were tested in batches. In order to evaluate the intra-stability of the analysis, the same sample was tested for 6 times in one day. Peaks with $\mathrm{m} / \mathrm{z}$ in the range of 1,000-10,000 Da were selected for calculation of the coefficient of variation. The results indicated that the coefficient of variation of intra-day and inter-day were $<20 \%$.

Spectra were analyzed by Flex Analysis software (version 3.0; Bruker Corporation), including spectrum smoothing, attenuation and standard peak processing (signal-to-noise ratio $>3$ ). The output data in Excel format, which contain $\mathrm{m} / \mathrm{z}$ and peak intensity values, were then normalized using NCBA 6.0 software (home made).

Classification procedure. Each spectrum obtained from the sample was characterized by a set of features using the CPT software, including background subtraction, normalization and integration of intensities. The disease control group was defined as patients that were administered with EGFR-TKI therapy for more than one month and their best treatment responses were $\mathrm{CR}, \mathrm{PR}$ or SD. The disease progression group was defined as patients that were administered with EGFR-TKI therapy within one month and the treatment response was evaluated as PD. Subsequently, two-thirds of the patients from each group were randomly selected for the training set of data in order to establish the classification algorithms. The software filters the significantly different polypeptides between the disease control and disease progression groups. The software then analyzed the intensities of these polypeptides and the best therapy response to establish the classification model. Briefly, the serum polypeptide fingerprints were analyzed by cluster analysis (Fig. 1). The results indicated that Quick Classifier (QC) was the optimal algorithm. QC is a single variable sorting algorithm that first sorts the average peak area of each group by P-value and calculates the weight. The model is then established and all parameters are unchanged. In total, 43 samples were used as a test group to verify the model. The test samples were classified as the disease control and progression groups using Clinpro Tools v2.1 software (Bruker Corporation) based on the classification model.

EGFR mutation status. EGFR mutations were identified according to previously established methods (29). Briefly, DNA was extracted from plasma using the QIAamp DNA Blood Mini kit (Qiagen GmbH, Hilden, Germany). EGFR mutation status was analyzed using the ADx-ARMS (amplification refractory mutation system) kit (Amoy Diagnostics, Xiamen, China), and all experiments and genotyping calling were performed following the manufacturer's instructions. This kit was approved by the Chinese Food and Drug Administration for in vitro diagnostics use, which detects the 29 most common EGFR mutations in lung cancer as described to date.

Statistical analysis. Statistical analysis was performed using SPSS (version 19; SPSS, Inc., Chicago, IL, USA). Kaplan-Meier survival curves of progression-free survival (PFS) and overall survival (OS) of patients in the disease control and disease progression groups were generated and compared using the Log-rank test. Time-to-event outcomes of disease control and disease progression group were analyzed using hazard ratios (HRs), which take into account the number and timing of events representing disease progression of PFS and mortality of OS, respectively. The results were presented as hazard ratios (HRs) with their $95 \%$ corresponding intervals (CIs). The association between clinical characteristics (stage, sex, age, performance status, smoking status, and histology) with survival, as well as the intensities of polypeptides in the classification model and EGFR gene expression were determined using the Mann-Whitney Test. Comparisons of the area under the peptide peaks between the disease control group and disease progression group were determined using an independent-sample t-test with ClinproTools software v2.1 (Bruker Corporation). $\mathrm{P}<0.05$ was considered to indicate a statistically significant difference. 
Table I. Characteristics of the patients with advanced non-small-cell lung cancer in the present study.

\begin{tabular}{|c|c|c|c|}
\hline \multirow[b]{2}{*}{ Characteristics } & \multicolumn{2}{|c|}{ Patients $(\mathrm{n}=103)$} & \multirow[b]{2}{*}{ P-value } \\
\hline & Disease control group, $(\mathrm{n}=51)$ & Disease progressive group, $(\mathrm{n}=52)$ & \\
\hline Age (years) & & & 0.105 \\
\hline Median & 57 & 59 & \\
\hline Range & $37-81$ & $33-79$ & \\
\hline Sex, n, (\%) & & & 0.200 \\
\hline Male & $28(54.9)$ & $35(67.3)$ & \\
\hline Female & $23(45.1)$ & $17(32.7)$ & \\
\hline Smoking history, n, (\%) & & & 0.013 \\
\hline Current or former smoker & $20(39.2)$ & $33(63.5)$ & \\
\hline Never smoked & $31(60.8)$ & $19(36.5)$ & \\
\hline Histology, n, (\%) & & & 0.579 \\
\hline Adenocarcinoma & $42(82.3)$ & $37(71.1)$ & \\
\hline Squamous-cell carcinoma & $3(5.9)$ & $11(21.2)$ & \\
\hline Others & $6(11.8)$ & $4(7.7)$ & \\
\hline Stage, n, (\%) & & & 0.449 \\
\hline IIIb & $5(9.8)$ & $3(5.8)$ & \\
\hline IV & $46(90.2)$ & $49(94.2)$ & \\
\hline EGFR-TKIs, n, (\%) & & & - \\
\hline Gefitinib & $11(21.6)$ & $13(25)$ & \\
\hline Erlotinib & $14(27.5)$ & $22(42.3)$ & \\
\hline Icotinib & $26(50.9)$ & $17(32.7)$ & \\
\hline RECIST, n, (\%) & & & - \\
\hline Partial response & $28(54.9)$ & - & \\
\hline Stable disease & $23(45.1)$ & - & \\
\hline Progressive disease & - & $52(100)$ & \\
\hline PFS (months) & & & $<0.0001$ \\
\hline Median & 9.6 & 0.9 & \\
\hline Range & $1.5-20$ & $0.5-1$ & \\
\hline OS (months) & & & $<0.0001$ \\
\hline Median & 13 & 4 & \\
\hline Range & $2.2-23$ & $0.6-21.8$ & \\
\hline EGFR mutation status, $\mathrm{n},(\%)$ & & & $<0.001$ \\
\hline Mutant & $25(49)$ & $3(5.8)$ & \\
\hline Exon 19 deletions & $11(21.6)$ & 0 & \\
\hline Exon 21 mutations & $12(23.5)$ & $3(5.8)$ & \\
\hline Other & $2(3.9)$ & 0 & \\
\hline Wild-type & $6(11.8)$ & $17(32.7)$ & \\
\hline Unknown & $20(39.2)$ & $32(61.5)$ & \\
\hline ECOG performance status, $\mathrm{n},(\%)$ & & & 0.620 \\
\hline $0-1$ & $44(86.3)$ & $43(82.7)$ & \\
\hline $2-3$ & $7(13.7)$ & $9(17.3)$ & \\
\hline
\end{tabular}

EGFR-TKI, epidermal growth factor receptor-tyrosine kinase inhibitor; RECIST, Response Evaluation Criteria for Solid Tumors; PFS, progression-free survival; OS, overall survival; ECOG, Eastern Cooperative Oncology Group.

\section{Results}

Patients. A total of 103 cases were included, with a median age of 58 years (range, 33-81 years). Of the total, 63 cases were male
(61.2\%), and around half (48.5\%) of the cases had a history of smoking. A total of 87 cases (84.5\%) had an ECOG score of 0-1, and 16 cases $(15.5 \%)$ had a score of $2-3$. The major pathological type was adenocarcinoma $(76.7 \%)$, followed by squamous 
Table II. Comparison of serum polypeptides peaks intensities between the disease progression and disease control groups.

\begin{tabular}{lccc}
\hline $\mathrm{m} / \mathrm{z}$ & $\begin{array}{c}\text { Progression group } \mathrm{I}(\mathrm{n}=30), \\
\text { average of peak area } \pm \text { SD }\end{array}$ & $\begin{array}{c}\text { Control group I }(\mathrm{n}=30), \\
\text { average of peak area } \pm \text { SD }\end{array}$ \\
\hline 3883.91 & $21.72 \pm 10.40$ & $44.41 \pm 15.41$ & $0.90^{\mathrm{a}}$ \\
7776.19 & $35.21 \pm 26.78$ & $121.06 \pm 64.54$ & $0.95^{\mathrm{a}}$ \\
9307.12 & $17.95 \pm 13.86$ & $74.58 \pm 45.55$ & $0.97^{\mathrm{a}}$ \\
4644.26 & $46.58 \pm 20.42$ & $87.98 \pm 34.08$ & $0.87^{\mathrm{a}}$ \\
2660.79 & $32.84 \pm 16.85$ & $76.54 \pm 46.48$ & $0.82^{\mathrm{a}}$ \\
3891.06 & $25.34 \pm 14.62$ & $41.24 \pm 13.72$ & $0.81^{\mathrm{a}}$ \\
7935.17 & $3.12 \pm 1.64$ & $6.84 \pm 4.31$ & $0.85^{\mathrm{a}}$ \\
2379.3 & $10.81 \pm 8.09$ & $21.54 \pm 12.04$ & $0.81^{\mathrm{a}}$ \\
\hline
\end{tabular}

${ }^{\mathrm{a}} \mathrm{P}<0.003$; AUC, area under the curve; SD, standard deviation.
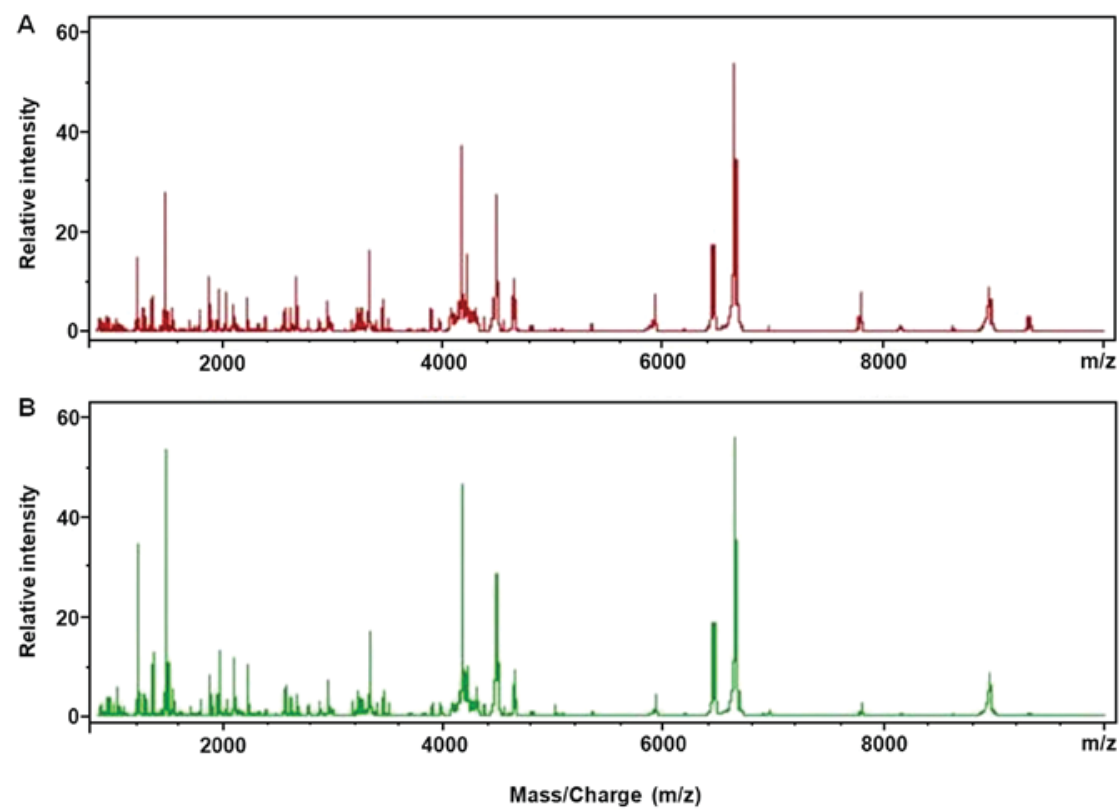

Figure 2. Serum polypeptides fingerprints in the training set: (A) Control group I and (B) progressive disease group I.

carcinoma (13.6\%), and other pathology cases accounted for $9.7 \%$. The study included 8 clinical stage IIIb cases $(7.8 \%)$ and 95 stage IV cases $(92.2 \%)$ (Table I).

A total of 51 samples were tested for EGFR gene mutations. The results indicated that around half of the cases (54.9\%) were EGFR mutants, including 11 (21.6\%) cases of exon 19 deletion mutation, $15(29.4 \%)$ cases of exon 21 point mutations and 2 cases (3.9\%) of exon 18 point mutations (Table I). The median of PFS for mutant and wild-type patients was 7.75 months and 1 month, respectively $(\mathrm{HR}=0.4905,95 \% \mathrm{CI}=0.2598-0.9260$, $\mathrm{P}=0.028$ ), and the median of OS was 11 months and 9 months, respectively $(\mathrm{HR}=0.7049,95 \% \mathrm{CI}=0.3919-1.268, \mathrm{P}=0.2431)$.

The median follow-up duration of all 103 cases was 9 months. A total of 51 cases with optimal treatment responses as CR or PR or SD following EGFR-TKIs therapy for more than one month were in the control group. The other 52 cases who were administrated with EGFR-TKIs within one month and whose responses evaluated as PD were counted in the progressive disease group.
Development of the classification model. The control and progressive disease cases were randomly divided into one training group and one test group by a ratio of 3:2 as previously described (18). The training group included 30 control cases (control group I) and 30 progressive disease cases (progressive group I). The other 43 patients were classified into the test group, including 21 cases in the control group (control group II) and 22 cases of progressive disease group (progressive group II).

The serum polypeptide fingerprints of control group I and progression group I are illustrated in Fig. 2. A total of 125 polypeptide peaks were identified from the fingerprints of control group I and progression group I by the CPT software. The significant difference was defined as AUC (area under the curve) $>0.8$ and $\mathrm{P}<0.003$. Based on these criteria, a total of 8 differential polypeptides peaks were obtained between the control group I and progressive group I, whose $\mathrm{m} / \mathrm{z}$ were in the range of 1,000-10,000 Da (Table II). Subsequently, the QC algorithm calculated 6 polypeptides in 

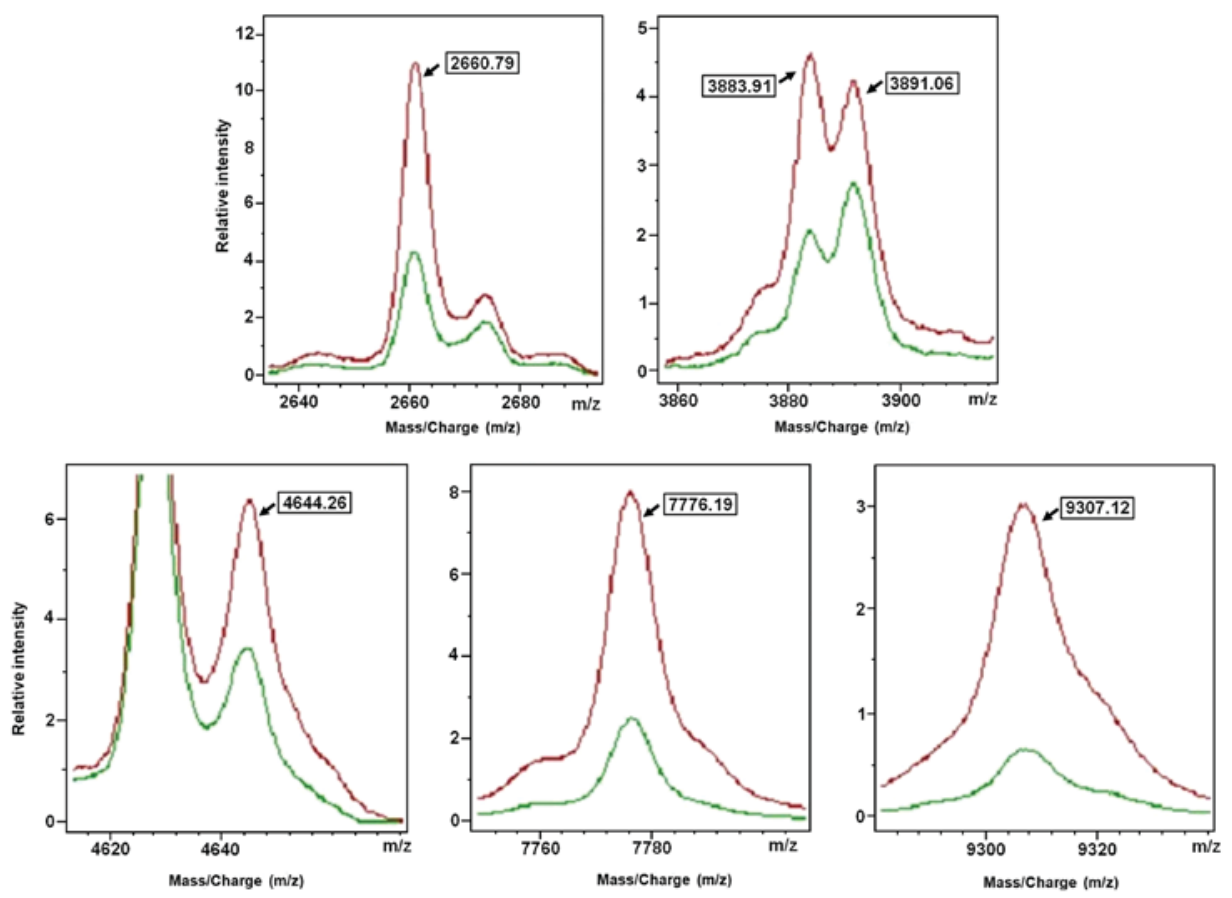

Figure 3. Six serum polypeptide peaks in the model. Red, control group I; green, progressive disease group I.

the optimal template, which was used to develop the classification model (Fig. 3 and Table III). It was defined that, when the 2660.79 Da peak area of the serum polypeptides was $76.54 \pm 46.48$, and 3883.91 Da peak area was $44.41 \pm 15.41$, and 3891.06 Da peak area was 41.24 \pm 13.72 , and 4644.26 Da peak area was $87.98 \pm 34.08$ range, and 7776.19 Da peak area was 121.06 \pm 64.54 , and 9307.12 Da peak area was $74.58 \pm 45.55$, the sample was considered from patients of the control group. By contrast, when 2660.79 Da peak area of the serum polypeptides was $32.84 \pm 16.85$, and 3883.91 Da peak area was $21.72 \pm 10.40$, and 3891.06 Da peak area was 25.34 \pm 14.62 , and 4644.26 Da peak area was $46.58 \pm 20.42$, and 7776.19 Da peak area was $35.21 \pm 26.78$, and 9307.12 Da peak area was $17.95 \pm 13.86$, the sample was considered from patients of the progressive disease groups. The result indicated that the identification and predictive rates of the model to clarify the disease control group were 90 and $93.16 \%$, respectively.

Validation of the classification model. A total of 43 patients in the test group were used to validate the classification model. Among 21 control cases, 16 cases were correctly classified. By contrast, among 22 cases in the progressive disease group, 18 cases were correctly classified by the classification model. Therefore, the sensitivity of the model was $76.2 \%$ (16/21), and the specificity was $81.8 \%(18 / 22)$. The accuracy rate was of the model $79.1 \%(34 / 43)$.

Correlation between EGFR mutation status and classification model. The correlation between the six polypeptides in the classification model and the expression of EGFR gene was further analyzed. A total of three polypeptides $(\mathrm{m} / \mathrm{z}=2660.79$, $\mathrm{m} / \mathrm{z}=4644.26$ and $\mathrm{m} / \mathrm{z}=9307.12$ ) were significantly different between EGFR mutant and wild-type patients $(\mathrm{P}=0.036$, $\mathrm{P}=0.025$ and $\mathrm{P}=0.037$, respectively). This meant results the stronger the expression of the polypeptides, the greater the
Table III. Mass spectral features used in the classification algorithm for matrix-assisted laser desorption ionization-time of flight mass spectrometry.

\begin{tabular}{lcc}
\hline $\mathrm{m} / \mathrm{z}$ & Maximum peak drift $(\%)$ & Weight \\
\hline 2660.79 & 0.1 & 0.0006 \\
3883.91 & 0.1 & 2.1662 \\
3891.06 & 0.1 & 0.0012 \\
4644.26 & 0.1 & 2.2672 \\
7776.19 & 0.1 & 3.2804 \\
9307.12 & 0.1 & 7.4200 \\
\hline
\end{tabular}

chance that the EGFR mutations occur. However, there was no statistically significant difference in the polypeptides, $\mathrm{m} / \mathrm{z}=3883.91, \mathrm{~m} / \mathrm{z}=3891.06$ and $\mathrm{m} / \mathrm{z}=7776.19$, between the two groups $(\mathrm{P}=0.784, \mathrm{P}=0.087$ and $\mathrm{P}=0.060$, respectively; Table IV $)$.

\section{Discussion}

Individualized treatment under the guidance of molecular markers is a research hotspot, and it is a current trend in advanced lung cancer treatment. Although EGFR mutation was a promising predictor of response to EGFR-TKIs treatment, many unfavorable conditions limited its usage. At present, some attempts have been taken to replace tissue specimens with blood, pleural effusion or other substitute samples that may contain tumor information for the detection of EGFR mutations $(13,15,30)$. However, a more constructive attempt is to establish a new predictor system using proteomic techniques. In the present study, a classification model was developed using six distinct $\mathrm{m} / \mathrm{z}$ features in a training set of patients. For validation in a test group, the sensitivity, 
Table IV. Correlation analysis of epidermal growth factor receptor mutation status and the polypeptides peaks intensities in the model.

\begin{tabular}{|c|c|c|c|c|c|c|}
\hline \multirow[b]{2}{*}{$\mathrm{m} / \mathrm{z}$} & \multicolumn{2}{|c|}{ Mutant $(\mathrm{n}=28)$} & \multicolumn{2}{|c|}{ Wild-type (n=23) } & \multirow[b]{2}{*}{ Statistics (Z score) } & \multirow[b]{2}{*}{ P-value } \\
\hline & Mean \pm SD & Median (IQR) & Mean \pm SD & Median (IQR) & & \\
\hline 2660.79 & $0.28 \pm 0.13$ & $0.29(0.19)$ & $0.27 \pm 0.13$ & $0.28(0.15)$ & -2.09 & 0.036 \\
\hline 3883.91 & $0.13 \pm 0.03$ & $0.12(0.04)$ & $0.13 \pm 0.03$ & $0.13(0.04)$ & 0.27 & 0.784 \\
\hline 3891.06 & $0.14 \pm 0.06$ & $0.13(0.06)$ & $0.17 \pm 0.07$ & $0.17(0.08)$ & 1.71 & 0.087 \\
\hline 4644.26 & $0.26 \pm 0.07$ & $0.25(0.14)$ & $0.22 \pm 0.06$ & $0.24(0.08)$ & 2.24 & 0.025 \\
\hline 7776.19 & $0.20 \pm 0.05$ & $0.20(0.07)$ & $0.16 \pm 0.07$ & $0.15(0.11)$ & -1.88 & 0.060 \\
\hline 9307.12 & $0.07 \pm 0.03$ & $0.07(0.04)$ & $0.05 \pm 0.03$ & $0.05(0.04)$ & -2.09 & 0.037 \\
\hline
\end{tabular}

$\mathrm{SD}$, standard deviation; IQR, interquartile range.

specificity and accuracy rate of the model were all $\sim 80 \%$. In addition, the intensities of the three polypeptides in the model were correlated with EGFR mutation status.

EGFR gene amplification is the most developed method in the clinic to predict EGFR-TKIs treatment responses $(31,32)$. EGFR gene amplification is also used to identify the cause of acquired resistance to EGFR-TKIs by repeated, real-time biopsy $(33,34)$. However, the difficulty of obtaining tissue samples and the presence of critical laboratory requirements limited the application of EGFR-TKI $(13,14,30)$.

In recent years, the development of a new prediction system has been imminently underway. One relatively new proteomic technology, MALDI-TOF MS, has been used as a tool to distinguish differentially expressed profiles in pretreatment serum for prediction of therapy response. The classification ability of the VeriStrat test based on the MALDI-TOF MS technique appears to be similar compared with tumor tissue-based assays (21). The algorithm in VeriStrat uses the integrated intensities of 8 mass spectral peaks and assigns a classification label either 'good' (VSG) or 'poor' (VSP) (21). Multivariate analysis of 111 patients with NSCLC that were treated with gefitinib indicated that the VSG group had longer PFS and OS compared with the VSP group (22). The prognostic value of the VeriStrat classification was further confirmed in the PROSE study, which is a biomarker-stratified, randomized phase III trial (35). A total of 285 cases of patients with advanced NSCLC were centrally randomized in a 1:1 ratio to the second-line treatment of erlotinib or standard chemotherapy (pemetrexe or dordocetaxel). According to VeriStrat classification and further stratified analysis, the overall survival of the VSG group was significantly improved compared with the VSP group. In addition, the survival of VSP patients who received chemotherapy was longer compared with those that were administered with erlotinib. However, the survival of the patients in the VSG group who received chemotherapy was similar to the patients that were administered with erlotinib (36).

The aforementioned studies indicated that the serum proteomic VeriStrat classification was particularly important in assisting treatment selection between chemotherapy and molecular targeted therapy for the second-line treatment of patients with wild-type EGFR and unknown EGFR status. It was recommended that the patients in the VSP group would receive chemotherapy. For VSG patients, the treatment response of molecular targeted therapy was similar compared with the response to chemotherapy.

In the present study, the classification model was developed based on serum polypeptides detected by MALDI-TOF MS. However, the $\mathrm{m} / \mathrm{z}$ values of 6 polypeptides entered in the present model were different from the findings of VeriStrat $(37,38)$. One reason might be that the VeriStrat algorithm was developed from patients with disease progression in less than one month and from patients with stable disease for more than six months (37), while the present model was based on differentially expressed spectra from patients with CR, PR or SD responses and from patients with PD. The differences in the definitions of treatment outcome may lead to identification of different polypeptides. On the other hand, the biological rationale for differential outcome according to MALDI-TOF MS is hypothesized to be associated with a systemic inflammatory response to tumors that promotes tumor growth and apoptotic resistance (39). The EGFR mutation rate in the Chinese population in the present study was different from the one targeted by VeriStrat, which may result in the induction of different inflammatory processes and thus different polypeptides. However, this hypothesis requires further investigation.

In a blinded fashion, the model was verified with an accuracy rate of $\sim 80 \%$. Lazzari et al (22) investigated the possible changes in VeriStrat classification from the pretreatment baseline to treatment withdrawal. It was identified that $30 \%$ of cases exhibited a change, and the majority of the changes were from 'good' to 'poor'. In addition, in 90\% of these cases where 'good' at the baseline was changed to 'poor', progression was associated with the development of new lesions (22). As the definition of 'disease control' used in the present model was not equivalent to the 'good' classification as used in VeriStrat, the change in classification from 'disease control' to 'progressive disease' and the change from progressive disease to disease control may have occurred. This may have resulted in false classification in the present study.

In the present study, a correlation between EGFR gene amplification in the plasma sample and expression intensities of 3 polypeptides peaks in the classification model was identified. However, other studies did report any significant correlations between VeriStrat classification and EGFR mutation status or 
KRAS mutations $(22,40,41)$. One may argue that blood samples were used to analyze EGFR mutation status while other studies detected EGFR amplifications using tissue specimens. However a number of studies have demonstrated that EGFR mutation in the plasma $(42-45)$ or serum $(46,47)$ was consistent with EGFR mutation status in tissue specimens $(42,43,46-48)$, and EGFR mutations in blood samples can be used as a predictor of treatment response from EGFR-TKIs $(42-45,48)$. It was hypothesized that the primary reason for the differences in $\mathrm{m} / \mathrm{z}$ values may be different host background between the present study and other studies (22,37,38,40,43-48).

As previously established, the rate of EGFR mutations is markedly higher in Asians compared with other ethnic groups such as Caucasian $(49,50)$. Consequently, we suggested that VeriStrat classification might be more useful to identify patients with primary or secondary resistance to EGFR-TKIs, while the classification model in the present study may focus on EGFR-TKI-sensitive populations.

There are two major limitations in the present study. One limitation was that the control group was not included. However, the model was verified in an additional separate study using a control group (data not shown). Another limitation was that smoking status may be a confounding factor when developing the model. Stratified analysis with a larger size of samples is required to avoid this bias.

The mechanisms of EGFR-TKI resistance and interventions for resistance are topical issues in clinical research. Using repeated biopsies and detection of EGFR mutations, it may be possible to identify the mechanisms underlying resistance and consequently lead to personalized therapy $(51,52)$.

However, repeat biopsy is more difficult to obtain due to poor material recovered by bronchoscopy and the invasiveness of the procedure, compared with repeat blood sampling $(53,54)$. By contrast, the dynamic monitoring of drug-resistant-associated proteomic indicators in blood samples may be more practical. Therefore, it is important to the future to observe the stability of the six polypeptides in the course of treatment and to monitor the potential correlation between the changes within the six polypeptides and disease progression.

In conclusion, the present study indicated that as a non-invasive and practical technique, MALDI-TOF MS analysis of peripheral blood may be a novel tool that can assist the selection of personalized treatment and a useful tool to complement conventional methods, particularly for patients where the availability of tissue samples is limited for EGFR detection. In addition, expanded and prospective studies will be considered for further verification of the dynamic and real-time property of the model.

\section{Acknowledgements}

The authors thank Dr Wei-Xia Wang and Miss Zi-He Wang (Department of Oncology, Affiliated Hospital of Academy of Military Medical Sciences, Beijing, China) for sample collection.

\section{Funding}

The present study was supported by the grant of the National Key Scientific Instrument and Equipment Development Project (grant no. 2011YQ170067).

\section{Availability of data and materials}

The datasets used and/or analyzed during the current study are available from the corresponding author on reasonable request.

\section{Authors' contributions}

JA and CHT drafted the manuscript. JA, CHT, NW, YL, JL, $\mathrm{BX}$ and $\mathrm{KH}$ carried out the MALDI-TOF MS experiment and analyzed the data. XYL, WFG and HJG collected the clinical samples and data of patients. XQL participated in the design and coordination of the study. All authors reviewed the draft manuscript, and read and approved the final version for submission.

\section{Ethics approval and consent to participate}

The present study was approved by the Ethics Committee of Academy of Military Medical Sciences (Beijing, China) in accordance with the medical research regulations of China and conformed to the provisions of the Declaration of Helsinki in 1995 (as revised in Tokyo 2004). All participants provided written informed consent.

\section{Consent for publication}

All participants provided written informed consent, and patient information was anonymized.

\section{Competing interests}

The authors have declared that no competing interests exist.

\section{References}

1. World Health Organization: Cancer. http://www.who.int/mediacentre/factsheets/fs297/en/. Accessed April 23, $2015 .$.

2. Stewart EL, Tan SZ, Liu G and Tsao MS: Known and putative mechanisms of resistance to EGFR targeted therapies in NSCLC patients with EGFR mutations-a review. Transl Lung Cancer Res 4: 67-81, 2015.

3. Pao W and Chmielecki J: Rational, biologically based treatment of EGFR-mutant non-small-cell lung cancer. Nat Rev Cancer 10: 760-774, 2010

4. Sequist LV, Joshi VA, Jänne PA, Muzikansky A, Fidias P, Meyerson M, Haber DA, Kucherlapati R, Johnson BE and Lynch TJ: Response to treatment and survival of patients with non-small cell lung cancer undergoing somatic EGFR mutation testing. Oncologist 12: 90-98, 2007.

5. Tsao MS, Sakurada A, Cutz JC, Zhu CQ, Kamel-Reid S, Squire J, Lorimer I, Zhang T, Liu N, Daneshmand M, et al: Erlotinib in lung cancer-molecular and clinical predictors of outcome. N Engl J Med 353: 133-144, 2005.

6. Taniguchi Y, Tamiya A, Nakahama K, Naoki Y, Kanazu M, Omachi N, Okishio K, Kasai T and Atagi S: Impact of metastatic status on the prognosis of EGFR mutation-positive non-small cell lung cancer patients treated with first-generation EGFR-tyrosine kinase inhibitors. Oncol Lett 14: 7589-7596, 2017.

7. Jackman D, Pao W, Riely GJ, Engelman JA, Kris MG, Jänne PA, Lynch T, Johnson BE and Miller VA: Clinical definition of acquired resistance to epidermal growth factor receptor tyrosine kinase inhibitors in non-small-cell lung cancer. J Clin Oncol 28: 357-360, 2010.

8. Laurila $\mathrm{N}$ and Koivunen JP: EGFR inhibitor and chemotherapy combinations for acquired TKI resistance in EGFR-mutant NSCLC models. Med Oncol 32: 205, 2015.

9. Hirsch FR, Varella-Garcia M, Bunn PA Jr, Franklin WA, Dziadziuszko R, Thatcher N, Chang A, Parikh P, Pereira JR, Ciuleanu T, et al: Molecular predictors of outcome with gefitinib in a phase III placebo-controlled study in advanced non-small-cell lung cancer. J Clin Oncol 24: 5034-5042, 2006. 
10. Lynch TJ, Bell DW, Sordella R, Gurubhagavatula S, Okimoto RA, Brannigan BW, Harris PL, Haserlat SM, Supko JG, Haluska FG, et al: Activating mutations in the epidermal growth factor receptor underlying responsiveness of non-small-cell lung cancer to gefitinib. N Engl J Med 350: 2129-2139, 2004.

11. Paez JG, Jänne PA, Lee JC, Tracy S, Greulich H, Gabriel S, Herman P, Kaye FJ, Lindeman N, Boggon TJ, et al: EGFR mutations in lung cancer: Correlation with clinical response to gefitinib therapy. Science 304: 1497-1500, 2004

12. Sharma SV, Bell DW, Settleman J and Haber DA: Epidermal growth factor receptor mutations in lung cancer. Nat Rev Cancer 7: 169-181, 2007.

13. Ellison G, Zhu G, Moulis A, Dearden S, Speake G and McCormack R: EGFR mutation testing in lung cancer: A reivew of available methods and their use for analysis of tumor tissue and cytology samples. J Clin Pathol 66: 79-89, 2013.

14. Kitamura A, Hosoda W, Sasaki E, Mitsudomi T and Yatabe Y: Immunohistochemical detection of EGFR mutation using mutation-specific antibodies in lung cancer. Clin Cancer Res 16 3349-3355, 2010.

15. Sandanayake NS, Camuzeaux S, Sinclair J, Blyuss O, Andreola F, Chapman MH, Webster GJ, Smith RC, Timms JF and Pereira SP: Identification of potential serum peptide biomarkers of biliary tract cancer using MALDI MS profiling. BMC Clin Pathol 14 7, 2014

16. Callesen AK, Madsen JS, Vach W, Kruse TA, Mogensen O and Jensen ON: Serum protein profiling by solid phase extraction and mass spectromety: A future diagnostics tools? Proteomics 9: $1428-1441,2009$

17. Lopez MF, Mikulskis A, Kuzdzal S, Golenko E, Petricoin EF III, Liotta LA, Patton WF, Whiteley GR, Rosenblatt K, Gurnani P, et al: A novel, high-throughput workflow for discovery and identification of serum carrier protein-bound peptide biomarker candidates in ovarian cancer samples. Clin Chem 53: 1067-1074, 2007.

18. Han KQ, Huang G, Gao CF, Wang XL, Ma B, Sun LQ and Wei ZJ: Identification of lung cancer patients by serum protein profiling using surface-enhanced laser desorption/ionization time-of-flight mass spectrometry. Am J Clin Oncol 31: 133-139, 2008.

19. Koopmann J, Zhang Z, White N, Rosenzweig J, Fedarko N, Jagannath S, Canto MI, Yeo CJ, Chan DW and Goggins M: Serum diagnosis of pancreatic adenocarcinoma using surface-enhanced laser desorption and ionization mass spectrometry. Clin Cancer Res 10: 860-868, 2004

20. Li J, Zhang Z, Rosenzweig J, Wang YY and Chan DW: Proteomics and bioinformatics approaches for identification of serum biomarkers to detect breast cancer. Clin Chem 48 : 1296-1304, 2002.

21. Taguchi F, Solomon B, Gregorc V, Roder H, Gray R, Kasahara K, Nishio M, Brahmer J, Spreafico A, Ludovini V, et al: Mass spectrometry to classify non-small-cell lung cancer patients for clinical outcome after treatment with epidermal growth factor receptor tyrosine kinase inhibitors: A multicohort cross-institutional study. J Natl Cancer Inst 99: 838-846, 2007.

22. LazzariC, Spreafico A, Bachi A, Roder H, Floriani I, Garavaglia D, Cattaneo A, Grigorieva J, Viganò MG, Sorlini C, et al: Changes in plasma mass-spectral profile in course of treatment of non-small cell lung cancer patients with epidermal growth factor receptor tyrosine kinase inhibitors. J Thorac Oncol 7: 40-48, 2012.

23. Hirsch FR and Bunn PA Jr: EGFR testing in lung cancer is ready for prime time. Lancet Oncol 10: 432-433, 2009.

24. Mitsudomi T, Kosaka T and Yatabe Y: Biological and clinical implications of EGFR mutations in lung cancer. Int J Clin Oncol 11: 190-198, 2006

25. Schiller JH, Harrington D, Belani CP, Langer C, Sandler A, Krook J, Zhu J and Johnson DH; Eastern Cooperative Oncology Group: Comparison of four chemotherapy regimens for advanced non-small-cell lung cancer. N Engl J Med 346: 92-98, 2002.

26. Sandler A, Gray R, Perry MC, Brahmer J, Schiller JH, Dowlati A, Lilenbaum R and Johnson DH: Paclitaxel-carboplatn alone or with bevacizumab for non-small-cell lung cancer. N Engl J Med 355: 2542-2550, 2006

27. Eisenhauer EA, Therasse P, Bogaerts J, Schwartz LH, Sargent D, Ford R, Dancey J, Arbuck S, Gwyther S, Mooney M, et al: New response evaluation criteria in solid tumors: Revised RECIST guideline (version 1.1). Eur J Cancer 45: 228-247, 2009.

28. Carlson RV, Boyd KM and Webb DJ: The revision of the Declaration of Helsinki: Past, present and future. Br J Clin Pharmacol 57: 695-713, 2004.
29. Liu X, Lu Y, Zhu G, Lei Y, Zheng L, Qin H, Tang C, Ellison G, McCormack R and Ji Q: The diagnostic accuracy of pleural effusion and plasma samples versus tumour tissue for detection of EGFR mutation in patients with advanced non-small cell lung cancer: Comparison of methodologies. J Clin Pathol 66: 1065-1069, 2013.

30. Kim CH, Kim SH, Park SY, Yoo J, Kim SK and Kim HK: Identification of EGFR mutations by immunohistochemistry with EGFR Mutation-specific antibodies in biopsy and resection specimens from pulmonary adenocarcinoma. Cancer Res Threat 47: 653-660, 2015.

31. Yang L, Tang C, Xu B, Wang W, Li J, Li X, Qin H, Gao H, $\mathrm{He} \mathrm{K}$, Song S and Liu X: Classification of epidermal growth factor receptor gene mutation status using serum proteomic profiling predicts tumor response in patients with stage IIIB or IV Non-small-cell lung cancer. PLoS One 10: e0128970, 2015.

32. Zhou J, Wang J, Zeng Y, Zhang X, Hu Q, Zheng J, Chen B, Xie B and Zhang WM: Implication of epithelial-mesenchymal transition in IGF1R-induced resistance to EGFR-TKIs in advanced non-small cell lung cancer. Oncotarget 6: 44332-44345, 2015.

33. Xu J, Wang $\mathrm{J}$ and Zhang S: Mechanisms of resistance to irreversible epidermal growth factor receptor tyrosine kinase inhibitors and therapeutic strategies in non-small cell lung cancer. Oncotarget 8: 90557-90578, 2017.

34. Mansuet-Lupo A, Zouiti F, Alifano M, Tallet A, Charpentier MC Ducruit V, Devez F, Lemaitre F, Laurent-Puig P, Damotte D and Blons H: Intratumoral distribution of EGFR mutations and copy number in metastatic lung cancer, what impact on the initial molecular diagnosis? J Transl Med 12: 131, 2014.

35. Gregorc V, Novello S, Lazzari C, Barni S, Aieta M, Mencoboni M, Grossi F, De Pas T, de Marinis F, Bearz A, et al: Predictive value of a proteomic signature in patients with non-small-cell lung cancer treated with second-line erlotinib or chemotherapy (PROSE): A biomarker-stratified, randomised phase 3 trial. Lancet Oncol 15: 713-721, 2014.

36. Lazzari C, Novello S, Barni S, Aieta M, De Marinis F, De Pas T, Grossi F, Mencoboni M, Bearz A, Floriani I, et al: Randomized proteomic stratified phase III study of second-line erlotinib (E) versus chemotherapy (CT) in patients with inoperable non-small cell lung cancer (PROSE). J Clin Oncol 31, 2013. DOI 10.1200/jco.2013.31.

37. Kuiper JL, Lind JS, Groen HJ, Roder J, Grigorieva J, Roder H, Dingemans AM and Smit EF: VeriStrat ${ }^{\circledR}$ has prognostic value in advanced stage NSCLC patients treated with erlotinib and sorafenib. Br J Cancer 107: 1820-1825, 2012.

38. Carbone DP, Ding K, Roder H, Grigorieva J, Roder J, Tsao MS, Seymour L and Shepherd FA: Prognostic and predictive role of the VeriStrat plasma test in patients with advanced non-small-cell lung cancer treated with erlotinib or placebo in the NCIC clinical trials group BR.21 tiral. J Thorac Oncol 7: 1653-1660, 2012.

39. Milan E, Lazzari C, Anand S, Floriani I, Torri V, Sorlini C, Gregorc V and Bachi A: SAA1 is over-expressed in plasma of non small cell lung cancer patients with poor outcome after treatment with epidermal growth factor receptor tyrosine-kinase inhibitors. J Proteomics 76: 91-101, 2012.

40. Amann JM, Lee JW, Roder H, Brahmer J, Gonzalez A, Schiller JH and Carbone DP: Genetic and proteomic features associated with survival after treatment with erlotinib in first-line therapy of non-small cell lung cancer in Eastern Cooperative Oncology Group 3503. J Thorac Oncol 5: 169-178, 2010.

41. Chung CH, Seeley EH, Roder H, Grigorieva J, Tsypin M, Roder J, Burtness BA, Argiris A, Forastiere AA, Gilbert J, et al: Detection of tumor epidermal growth factor receptor pathway dependence by serum mass spectrometry in cancer patients. Cancer Epidemiol Biomarkers Prev 19: 358-365, 2010.

42. Bai H, Mao L, Wang HS, Zhao J, Yang L, An TT, Wang X, Duan CJ, Wu NM, Guo ZQ, et al: Epidermal growth factor receptor mutations in plasma DNA samples predict tumor response in Chinese patients with stages IIIB to IV non-small-cell lung cancer. J Clin Oncol 27: 2653-2659, 2009 .

43. He C, Liu M, Zhou C, Zhang J, Ouyang M, Zhong N and Xu J: Detection of epidermal growth factor receptor mutations in plasma by mutant-enriched PCR assay for prediction of the response to gefitinib in patients with non-small-cell lung cancer. Int J Cancer 125: 2393-2399, 2009.

44. Jian G, Songwen Z, Ling Z, Qinfang D, Jie Z, Liang T and Caicun Z: Prediction of epidermal growth factor receptor mutations in the plasma/pleural effusion to efficacy of gefitinib treatment in advanced non-small cell lung cancer. J Cancer Res Clin Oncol 136: 1341-1347, 2010. 
45. Mack PC, Holland WS, Burich RA, Sangha R, Solis LJ, Li Y, Beckett LA, Lara PN Jr, Davies AM and Gandara DR: EGFR mutations detected in plasma are associated with patient outcomes in erlotinib plus docetaxel-treated non-small cell lung cancer. J Thorac Oncol 4: 1466-1472, 2009.

46. Kimura H, Kasahara K, Shibata K, Sone T, Yoshimoto A, Kita T, Ichikawa Y, Waseda Y, Watanabe K, Shiarasaki H, et al: EGFR mutation of tumor and serum in gefitinib-treated patients with chemotherapy-naive non-small cell lung cancer. J Thorac Oncol 1: 260-267, 2006.

47. Kimura H, Suminoe M, Kasahara K, Sone T, Araya T, Tamori S, Koizumi F, Nishio K, Miyamoto K, Fujimura M and Nakao S: Evaluation of epidermal growth factor receptor mutation status in serum DNA as a predictor of response to gefitinib (IRESSA). Br J Cancer 97: 778-784, 2007.

48. Kuang Y, Rogers A, Yeap BY, Wang L, Makrigiorgos M, Vetrand K, Thiede S, Distel RJ and Jänne PA: Noninvasive detection of EGFR T790M in gefitinib or erlotinib resistant non-small cell lung cancer. Clin Cancer Res 15: 2630-2636, 2009.

49. Chen YM: Update of epidermal growth factor receptor-tyrosine kinase inhibitors in non-small-cell lung cancer. J Chin Med Assoc 76: 249-257, 2013.

50. Shiau CJ, Babwah JP, da Cunha Santos G, Sykes JR, Boerner SL, Geddie WR, Leighl NB, Wei C, Kamel-Reid S, Hwang DM and Tsao MS: Sample features associated with success rates in population-based EGFR mutation testing. J Thorac Oncol 9: 947-956, 2014.
51. Socinski MA, Villaruz LC and Ross J: Understanding mechanisms of resistance in the epithelial growth factor receptor in non-small cell lung cancer and the role of biopsy at progression. Oncologist 22: 3-11, 2017.

52. Doebele RC, Pilling AB, Aisner DL, Kutateladze TG, Le AT, Weickhardt AJ, Kondo KL, Linderman DJ, Heasley LE, Franklin WA, et al: Mechanisms of resistance to crizotinib in patients with AKL gene rearranged non-small cell lung cancer. Clin Cancer Res 18: 1472-1482, 2012.

53. Travis WD, Brambilla E, Noguchi M, Nicholson AG, Geisinger K, Yatabe Y, Powell CA, Beer D, Riely G, Garg K, et al: International association for the study of lung Cancer/American Thoracic Society/European respiratory society: International multidisciplinary classification of lung adenocarcinoma: Executive summary. Proc Am Thorac Soc 8: 381-385, 2011.

54. Ou SH, Bartlett CH, Mino-Kenudson M, Cui J and Iafrate AJ: Crizotinib for the treatment of ALK-rearranged non-small cell lung cancer: A success story to usher in the second decade of molecular targeted therapy in oncology. Oncologist 17: 1351-1375, 2012. 